\title{
Adenovirus-Mediated Transfer of the Herpes Simplex Virus Thymidine Kinase Gene Inhibits Vascular Smooth Muscle Cell Proliferation and Neointima Formation Following Balloon Angioplasty of the Rat Carotid Artery
}

\author{
Mark W. Chang,* Takeshi Ohno, ${ }^{\dagger}$ David Gordon, ${ }^{\star}$ Min Min Lu,* \\ Gary J. Nabel, ${ }^{\dagger \S}$ Elizabeth G. Nabel, $\$$ and Jeffrey M. Leiden*ll \\ Departments of ${ }^{*}$ Medicine and "Pathology, University of Chicago, \\ Chicago, Illinois, U.S.A. Departments of ${ }^{+}$Medicine and ${ }^{\ddagger}$ Pathology \\ and the ${ }^{\S}$ Howard Hughes Medical Institute, University of Michigan, \\ Ann Arbor, Michigan, U.S.A.
}

\begin{abstract}
Background: Vascular smooth muscle cell (VSMC) proliferation following arterial injury plays a critical role in a variety of vascular proliferative disorders, including atherosclerosis and restenosis after balloon angioplasty. In this study, we tested the hypothesis that localized arterial infection at the time of balloon angioplasty with an adenovirus (ADV-tk) encoding the herpes simplex virus thymidine kinase gene (HSVtk), followed by systemic ganciclovir administration, can inhibit VSMC proliferation and neointima formation in a well-characterized model of arterial injury and restenosis.

Materials and Methods: The left carotid arteries of 31 male Sprague-Dawley rats were subjected to balloon angioplasty and immediately infected with $2 \times$ $10^{9} \mathrm{pfu}$ of either ADV-tk or a control adenovirus that does not encode a recombinant protein (ADV- $\Delta E 1)$. Twenty-four hours after injury, animals from each experimental group were randomized to receive a course of systemic ganciclovir (ADV-tk/+GC, ADV$\Delta \mathrm{E} 1 /+\mathrm{GC}$ ) or saline (ADV-tk/-GC, ADV- $\Delta \mathrm{El} /-\mathrm{GC})$. VSMC DNA synthesis was measured by 5'-bromodeoxyuridine (BrdU) incorporation 2-4 days after balloon injury. The extent of restenosis, expressed as the neointima to media (I/M) area ratio was determined by digital planimetry 20 days after balloon injury in each of the four treatment groups. Immunohistochemistry using a mAb to von Willebrand factor (vWF) was used to determine the effects of ADV-tk infection and ganciclovir treatment on re-endothelialization of the carotid arteries 20 days following balloon angioplasty.
\end{abstract}

\begin{abstract}
Results: Forty-one percent of the medial VSMCs in the ADV-tk/-GC arteries were labeled with BrdU 4 days after balloon injury. In contrast, ADV-tk infected animals that were treated with systemic ganciclovir (ADV-tk/+GC) displayed a $40 \%$ reduction in BrdUstaining medial VSMCs $(p<0.03)$. I/M area ratios of the three control groups were $1.17 \pm 0.18$ (ADV-tk/ $-\mathrm{GC}, n=5), 1.15 \pm 0.10(\mathrm{ADV}-\Delta \mathrm{E} 1 /+\mathrm{GC}, n=6)$, and $0.91 \pm 0.08(\mathrm{ADV}-\Delta \mathrm{E} 1 /-\mathrm{GC}, n=6)$. These differences were not statistically significant $(p>0.05)$. In contrast, the $\mathrm{ADV}-\mathrm{tk} /+\mathrm{GC}$ animals $(n=6)$ displayed an $\mathrm{I} / \mathrm{M}$ area ratio of $0.49 \pm 0.13$ which was significantly lower than that seen in each of the three control groups $(p<0.02)$. None of the treated animals showed evidence of significant organ toxicity at autopsy. A regenerated endothelium was observed in the ADVtk/ + GC animals 20 days after balloon injury.

Conclusions: Localized arterial infection with ADV-tk at the time of balloon angioplasty followed by systemic ganciclovir therapy reduces VSMC proliferation and neointimal expansion in the rat carotid artery injury model. Moreover, combined treatment with ADV-tk and systemic ganciclovir does not result in systemic toxicity and appears to selectively eliminate proliferating VSMCs, while preserving the capacity of the injured arterial segments to re-endothelialize within 3 weeks of injury. Taken together, these results support the feasibility of using this gene therapy approach for the treatment of human vascular proliferative disorders.
\end{abstract}




\section{INTRODUCTION}

Vascular smooth muscle cells (VSMCs) play an important role in both the normal and pathological responses of the arterial wall to injury (1). Nonproliferating $\left(G_{O}\right)$ VSMCs are normally localized to the arterial tunica media where they regulate vascular tone and local perfusion in response to a variety of neurohumoral signals. Arterial injury results in the migration of VSMCs from the tunica media into the intima where they proliferate and elaborate extracellular matrix $(1,2,3)$. This proliferation contributes to the pathogenesis of a number of cardiovascular disorders, including atherosclerosis and restenosis which occurs in $30-50 \%$ of patients following percutaneous transluminal coronary angioplasty (PTCA) (2-5). Molecular approaches designed to limit VSMC proliferation specifically at sites of arterial injury could both lead to a better understanding of the pathogenesis of vascular proliferative disorders and aid in the rational design of novel gene-based therapies for these disorders in humans.

Herpes Simplex virus thymidine kinase (HSV-tk) phosphorylates the nucleoside analog ganciclovir, converting it into an active form that inhibits DNA synthesis and kills proliferating cells $(6,7)$. Recent studies have demonstrated that forced expression of the HSV-tk gene, when combined with ganciclovir treatment can be used as an effective cytotoxic therapy for tumor cells both in vitro and in vivo (8-13). Interestingly, in these studies, expression of the HSV-tk gene in only a small proportion of the tumor cells resulted in widespread cell death due to a "bystander effect." We and others have recently demonstrated that replication-defective adenoviruses can be used to efficiently transfer recombinant genes into VSMCs in localized segments of the arterial wall in vivo (14-17). In the studies described in this report, we have tested the hypothesis that localized infection of the arterial wall at the time of balloon angioplasty with a replication-defective adenovirus encoding the HSV-tk gene when combined with systemic ganciclovir treatment can be used to inhibit VSMC proliferation and neointima formation in the rat carotid artery model of vascular injury and restenosis.

\section{MATERIALS AND METHODS}

Recombinant Adenoviruses.

ADV-tk is an E1- and E3-deleted, replicationdefective, Ad 5-derived adenovirus which con- tains the HSV-tk gene under the transcriptional control of a polyoma enhancer/promoter (15). The ADV- $\Delta \mathrm{E} 1$ control virus is identical to ADV-tk but lacks the HSV-tk gene and the polyoma enhancer/promoter (15). Both viruses were prepared and grown as high titer stocks in 293 cells as described previously (14). All virus stocks were purified by centrifugation in discontinuous $\mathrm{CsCl}$ gradients and dialyzed against phosphatebuffered saline (PBS) (14). Viruses were diluted for storage in $13 \%$ glycerol-PBS solution to yield a final titer of $7.5 \times 10^{9} \mathrm{pfu} / \mathrm{ml}$.

\section{In Vivo Gene Transfer and Drug Therapy}

Localized arterial infection with the recombinant adenoviruses following balloon injury was performed as described previously (14). Briefly, the left common carotid arteries of adult male Sprague-Dawley rats were injured by dilatation using a 2 French Fogarty catheter (18). Following injury, the instrumented carotid artery segments were isolated using microvascular clamps. A 24-gauge intravenous catheter was introduced into the lumen of each isolated $1-\mathrm{cm}$ segment and $2 \times 10^{9}$ pfu of either ADV-tk or ADV- $\triangle E F 1$ was instilled for $5 \mathrm{~min}$. Following infection, the catheter was removed and blood flow to the common carotid artery was restored by release of the microvascular clamps. Twenty-four hours after balloon injury and adenovirus infection, animals were randomized to receive either ganciclovir (25 mg/kg intraperitoneally) (a generous gift from Syntex, Palo Alto, CA) or saline twice daily for a total of 6 days. All animal experimentation was performed in accordance with NIH guidelines in the A. J. Carlson Animal Research Facility of the University of Chicago.

\section{Quantitation of VSMC DNA Synthesis}

Medial VSMC DNA synthesis was measured by BrdU incorporation in vivo as described previously (14). Two days after balloon injury and virus infection, animals received four subcutaneous injections of BrdU ( $25 \mathrm{mg} / \mathrm{kg}$ every $12 \mathrm{hr}$ ). Animals were sacrificed 4 days after balloon injury and the carotid arteries were fixed in situ by intravascular administration of $4 \%$ paraformaldehyde $(4,19,20)$. The carotid arteries were dissected free of connective tissue and paraffin-embedded. Deparaffinized $5-\mu \mathrm{m}$ sections were treated with $3 \% \mathrm{H}_{2} \mathrm{O}_{2}$ in methanol and permeablized by incubation in $0.4 \%$ pepsin and $3.3 \mathrm{M}$ $\mathrm{HCl}$. Sections were blocked by incubation for 20 
minutes at room temperature in $1.5 \%$ horse serum and incubated overnight at $4^{\circ} \mathrm{C}$ with a $1: 100$ dilution of an $\alpha$-BrdU mAb (Becton-Dickinson, San Jose, CA). The sections were then incubated for $30 \mathrm{~min}$ at room temperature with a 1:200 dilution of biotinylated horse $\alpha$-mouse Ig antiserum, followed by a 30-min incubation at room temperature with avidin-conjugated horseradish peroxidase (Vectastain Elite $\mathrm{ABC}$ kit; Vector laboratories, Burlingame, CA). Sections were then treated with diaminobenzidine (DAB) and counterstained with hematoxylin and eosin. Total nuclei and BrdU-positive nuclei were counted manually. At least 500 cells from two sections taken at least $1 \mathrm{~mm}$ apart were assessed in duplicate for each animal. To ensure that all animals received adequate doses of BrdU, sections of terminal ileum were used as positive controls. All slides were coded and determinations were performed by an observer blinded to the experimental conditions. Statistical analyses were performed using Sigmaplot (Jandel Scientific, Corte Madera, CA).

\section{Histological Analyses}

Carotid arteries were harvested as described previously (14) 20 days after balloon injury and virus infection. Arteries were paraffin-embedded and $5-\mu \mathrm{M}$ sections were stained with hematoxylin and eosin. Neointimal and medial boundaries were determined on coded slides in two independent laboratories (JML and EGN) by investigators who were blinded to the experimental conditions. Areas were determined using digital planimetry of tissue sections using MOCHA software (Jandel Scientific, Corte Madera, CA) and the Image-1 System (Universal Imaging, Westchester, PA) as described previously $(14,21)$. The neointimal and medial (I/M) crosssectional areas were measured from four sections of each artery. Each section was obtained from the $1-\mathrm{cm}$ segment of common carotid artery that was subjected to both balloon injury and ADV infection. The mean of these four determinations was used to calculate the $\mathrm{I} / \mathrm{M}$ cross-sectional ratio for each animal. Tissue samples were also obtained from the brain, heart, lung, liver, spleen, aorta, skeletal muscle, kidney, intestine, and testes from each animal, and hematoxylin and eosin stained sections from each tissue were examined for pathology by an experimental pathologist (DG) blinded to the experimental conditions.

\section{Immunohistochemistry}

Carotid arteries harvested 20 days after balloon injury were fixed and embedded as described above. Immunostaining for vWF was performed as described previously (14). Briefly, $5-\mu \mathrm{m}$ sections were stained with a commercially available $\alpha$-vWF mAb (Dako, Santa Barbara, CA) followed by a biotinylated goat anti-mouse IgG using an automatic immunostainer (Ventana Immunosystems, Tucson, AZ). Slides were developed with avidin-conjugated alkaline phosphatase and fast red-naphthol (Ventana Immunosystems) according to the manufacturer's instructions. In negative control experiments, the same sections were stained with an isotype matched control mAb. Sections of human tonsil were used as positive controls.

\section{Statistical Analysis}

All values are expressed as mean \pm SEM. Statistical analyses were performed using Sigmaplot software (Jandel Scientific, Corte Madere, CA) on an Apple Macintosh Quadra computer. The Student's $t$ test was used to evaluate differences between the experimental groups.

\section{RESULTS}

\section{Inhibition of VSMC Proliferation by ADV-tk Infection Followed by Systemic Ganciclovir Therapy}

Balloon injury of the rat carotid artery is a well characterized animal model of arterial restenosis that has been shown to be highly dependent upon VSMC proliferation and migration $(14,16,18-20)$. Previous studies in this model have shown that medial VSMCs begin to proliferate within 2 days after balloon injury $(14,18)$. Medial VSMC proliferation reaches a peak within 4 days after injury, with approximately $40 \%$ of the cells proliferating as measured by incorporation of BrdU (14). Between 4 and 6 days after injury, significant numbers of proliferating VSMCs can be detected in the neointima of the injured vessel. By 20 days after injury, all of the arteries demonstrate significant neointima formation and VSMC proliferation is no longer detectable in either the media or the neointima of the injured vessel $(14,18,19)$.

To determine the effects of localized ADV-tk infection plus systemic ganciclovir treatment on VSMC proliferation following balloon injury of 


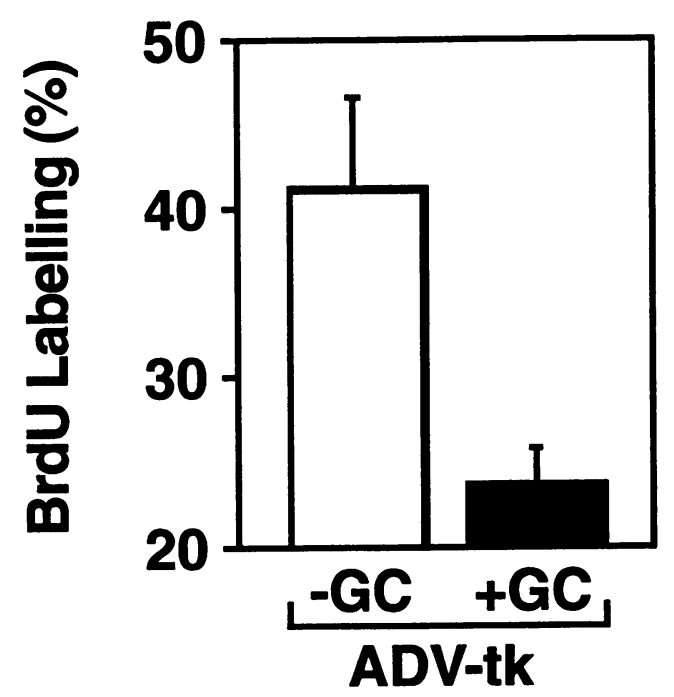

FIG. 1. Inhibition of medial VSMC DNA synthesis by ADV-tk/+GC

Rat carotid arteries were infected with $2 \times 10^{9} \mathrm{pfu}$ of ADV-tk for 5 min immediately following balloon injury. Animals were treated for 3 days with systemic ganciclovir (ADV-tk/+GC) or saline (ADV-tk/ -GC) administered by intraperitoneal injection beginning $24 \mathrm{hr}$ after balloon injury and adenovirus infection. Medial VSMC proliferation was measured by BrdU incorporation between 2 and 4 days after balloon injury and adenovirus infection.

the rat carotid artery, injured arterial segments were infected with $2 \times 10^{9} \mathrm{pfu}$ of ADV-tk for 5 min immediately following balloon injury. We have previously demonstrated that this protocol results in efficient infection of and recombinant gene expression in medial VSMCs in the injured arterial segment $(14,15)$. Animals were treated with systemic ganciclovir administered by intraperitoneal injection beginning $24 \mathrm{hr}$ after balloon injury and adenovirus infection. Medial VSMC proliferation was measured by BrdU incorporation between 2 and 4 days after balloon injury and adenovirus infection. Control animals were infected with identical amounts of ADV-tk but did not receive systemic ganciclovir therapy (ADV-tk/-GC). As shown in Fig. 1, ADV-tk in- fection plus ganciclovir treatment significantly inhibited medial VSMC DNA synthesis. Fortyone percent of the medial VSMCs from ADV-tkinfected control animals that did not receive ganciclovir displayed evidence of DNA synthesis as measured by BrdU staining. In contrast, only $23 \%$ of the VSMCs in the ADV-tk/ + GC animals incorporated $\mathrm{BrdU}$, representing a $40 \%$ reduction in the ADV-tk/+GC group $(p<0.03)$. These results demonstrated that ADV-tk infection combined with systemic ganciclovir therapy results in an early and significant reduction in medial VSMC proliferation following balloon injury.

\section{Inhibition of Neointima Formation by Localized Infection with ADV-tk Followed by Systemic Ganciclovir Therapy}

To directly determine the effects of ADV-tk infection and systemic ganciclovir therapy on neointimal formation following balloon injury of the rat carotid artery, animals were infected with $2 \times$ $10^{9} \mathrm{pfu}$ of ADV-tk for $5 \mathrm{~min}$ immediately following balloon injury. They were then treated with systemic ganciclovir ( $25 \mathrm{mg} / \mathrm{kg}$ IP twice daily) for 6 days beginning 24 hours after balloon injury and ADV-tk infection. Twenty days after injury, animals were sacrificed, and the extent of neointima formation, expressed as the neointi$\mathrm{mal} / \mathrm{medial}(\mathrm{I} / \mathrm{M})$ area ratio, was measured by digital planimetry. Three control groups were used in these experiments. The first group $(n=6)(\mathrm{ADV}-\Delta \mathrm{E} 1 /-\mathrm{GC})$ was infected with $2 \times$ $10^{9} \mathrm{pfu}$ of a control adenovirus lacking the HSV-tk gene and received weight-adjusted systemic saline rather than ganciclovir treatment. The second group $(n=6)(\mathrm{ADV}-\Delta \mathrm{E} 1 /+\mathrm{GC})$ was infected with the control virus lacking the HSV-tk gene and received systemic ganciclovir therapy for 6 days as described above. The third group $(n=5)$ (ADV-tk/-GC) was infected with $2 \times 10^{9}$ pfu of ADV-tk but received systemic treatment with an equivalent volume of saline rather than ganciclovir.

Carotid arteries from the three control

FIG. 2. Inhibition of neointimal formation by ADV-tk/+GC following arterial injury (opposite)

Adult rats underwent carotid artery angioplasty and adenovirus-mediated gene transfer with ADV-tk or ADV- $\Delta \mathrm{E} 1$ as described in Materials and Methods, and were then randomized to receive systemic therapy with either ganciclovir (ADV-tk/+GC or ADV- $\Delta \mathrm{E} 1 /+\mathrm{GC}$ ) or saline (ADV-tk/-GC or ADV- $\Delta \mathrm{E} 1 /-\mathrm{GC}$ ) for 6 days. Carotid arteries were obtained for analysis 20 days following arterial injury and gene transfer. Representative photomicrographs from ADV- $\Delta \mathrm{E} 1 /-\mathrm{GC}$ (A and B), ADV- $\Delta \mathrm{E} 1 /+\mathrm{GC}(\mathrm{C}$ and $\mathrm{D}), \mathrm{ADV}-\mathrm{tk} /-\mathrm{GC}$ (E and F), or ADV-tk/+GC (G and H) treated arteries are shown. (A, C, E, and G) Magnification 100×; (B, D, F, and H) 400×. Arrows delineate the internal elastic lamina. Note the significant reduction in neointima formation in the ADV-tk/+GC artery. 

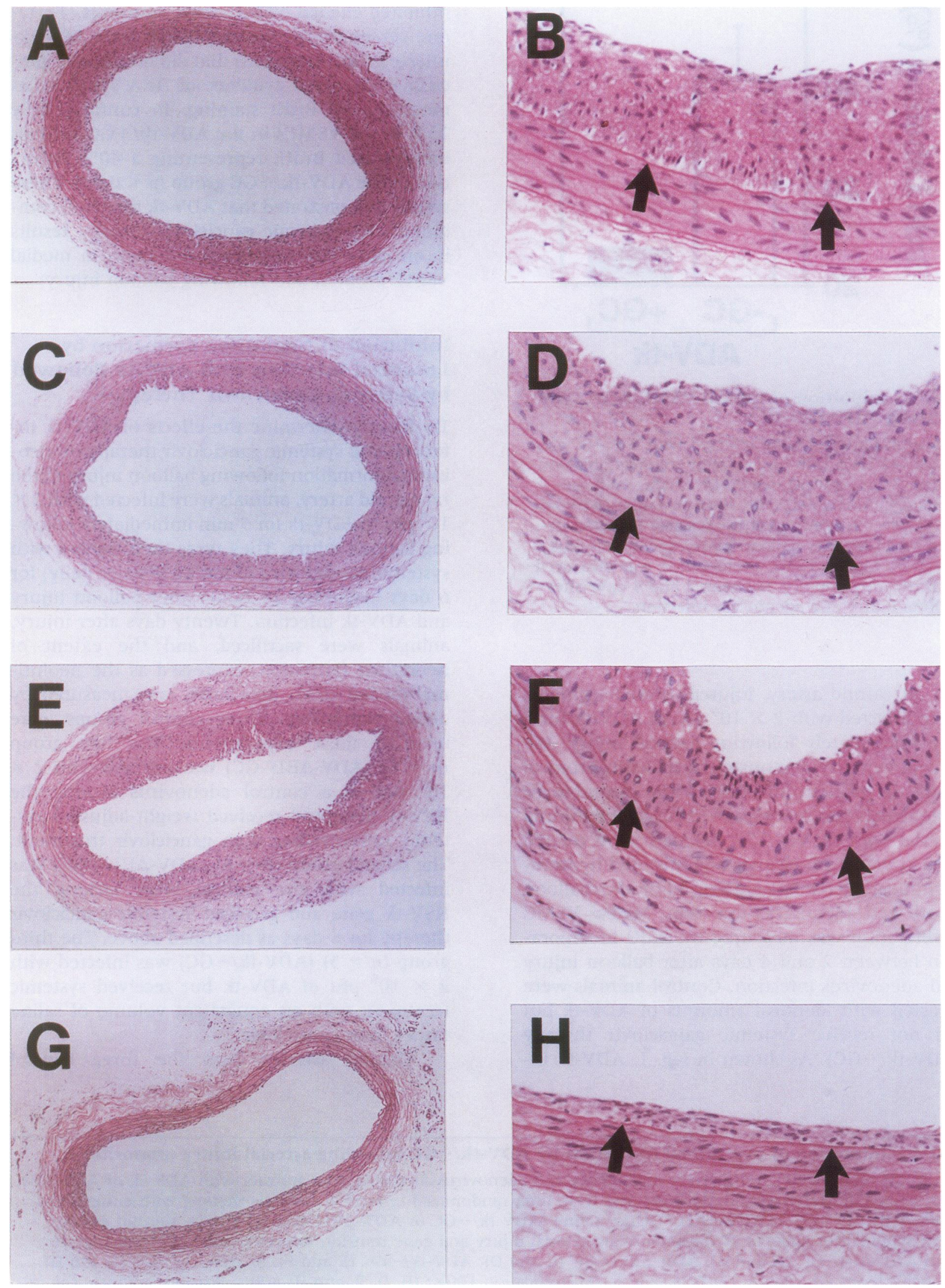


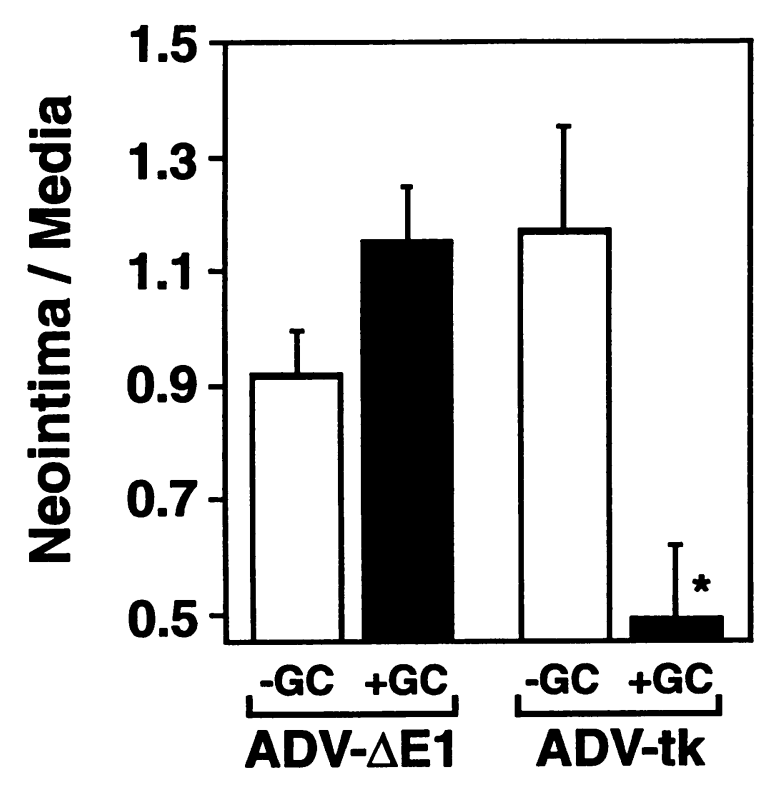

FIG. 3. Inhibition of restenosis by ADV-tk/ +GC following arterial injury

Ratios of the mean cross-sectional areas of the neointima and media in carotid arteries analyzed 20 days after balloon injury are shown. ${ }^{*} p<0.02$ as compared with control groups. There was no significant difference observed between each of the control groups $(p>0.05)$.

groups displayed $\mathrm{I} / \mathrm{M}$ area ratios of $1.17 \pm 0.18$ (ADV-tk/-GC), $1.15 \pm 0.10(\mathrm{ADV}-\Delta \mathrm{E} 1 /+\mathrm{GC})$, and $0.91 \pm 0.08$ (ADV- $\Delta$ El/-GC) (Fig. 3). These $\mathrm{I} / \mathrm{M}$ ratios were not statistically different from each other $(P>0.05)$. In contrast, the combination of ADV-tk infection and systemic ganciclovir therapy resulted in an $\mathrm{I} / \mathrm{M}$ ratio of $0.49 \pm 0.13$, which represented a $58 \%$ reduction as compared with that in the ADV-tk/-GC control group, a $57 \%$ reduction as compared with the $\mathrm{I} / \mathrm{M}$ ratio of the ADV- $\triangle \mathrm{E} 1 /+\mathrm{GC}$ control animals, and a $46 \%$ reduction as compared with the $\mathrm{I} / \mathrm{M}$ ratio in the ADV- $\Delta$ E $1 /-G C$ treated controls $(p<0.02)$. Thus, localized ADV-tk infection at the time of arterial injury, followed by systemic administration of ganciclovir resulted in significant reductions in both VSMC proliferation and neointimal formation in the rat carotid artery model of restenosis.

\section{Reendothelialization Following ADV-tk Infection and Systemic Ganciclovir Therapy}

Reendothelialization has been shown to play an important role in preventing thrombosis and inhibiting VSMC proliferation during the normal vascular response to injury (22-26). Reendothelialization of injured arterial segments is mediated by the repopulation of endothelial cells from uninjured segments of the arterial tree adjacent to the site of injury (18). Replication-defective adenovirus vectors have been shown to efficiently infect endothelial cells in vitro and in vivo $(17,27)$. Thus, it was possible that ADV-tk infection followed by systemic ganciclovir therapy would inhibit the normal reendothelialization of the rat carotid artery following balloon angioplasty. To address this possibility, we used immunohistochemistry with an endothelial cell-specific $\alpha$-vWF mAb to assess the extent of reendothelialization 20 days following ADV-tk infection and systemic ganciclovir therapy. As shown in Fig. 4A, the luminal surface of these arterial segments was lined with a monolayer of endothelial cells that stain with the $\alpha$-vWF mAb. Thus, ADV-tk infection and ganciclovir therapy inhibits VSMC proliferation and neointimal formation while allowing efficient reendothelialization of the injured arterial segment within 20 days.

Lack of Significant Tissue Toxicity in the ADV-tk-Infected Animals Receiving Systemic Ganciclovir Therapy

Because replication-defective adenovirus vectors have been shown to efficiently infect a wide variety of cell types in vitro and in vivo $(17,27-$ 32 ), it was possible that intravascular infection with ADV-tk followed by systemic ganciclovir therapy would result in significant cytotoxicity in a variety of organs in vivo. To address this issue, tissue samples from brain, heart, lung, aorta, liver, kidney, spleen, intestine, testes, and skeletal muscle were examined by light microscopy. No significant pathologic lesions were observed in these tissues from animals in the four experimental groups. Of note, the infected carotid arteries showed occasional mononuclear cell infiltrates in the adventitia but no medial or neointimal inflammation, necrosis, or aneurysm formation.

\section{DISCUSSION}

Percutaneous transluminal coronary angioplasty (PTCA) remains a mainstay of therapy for symptomatic coronary artery disease $(4,5)$. While this procedure is initially successful in relieving critical arterial stenoses in greater than $95 \%$ of pa- 


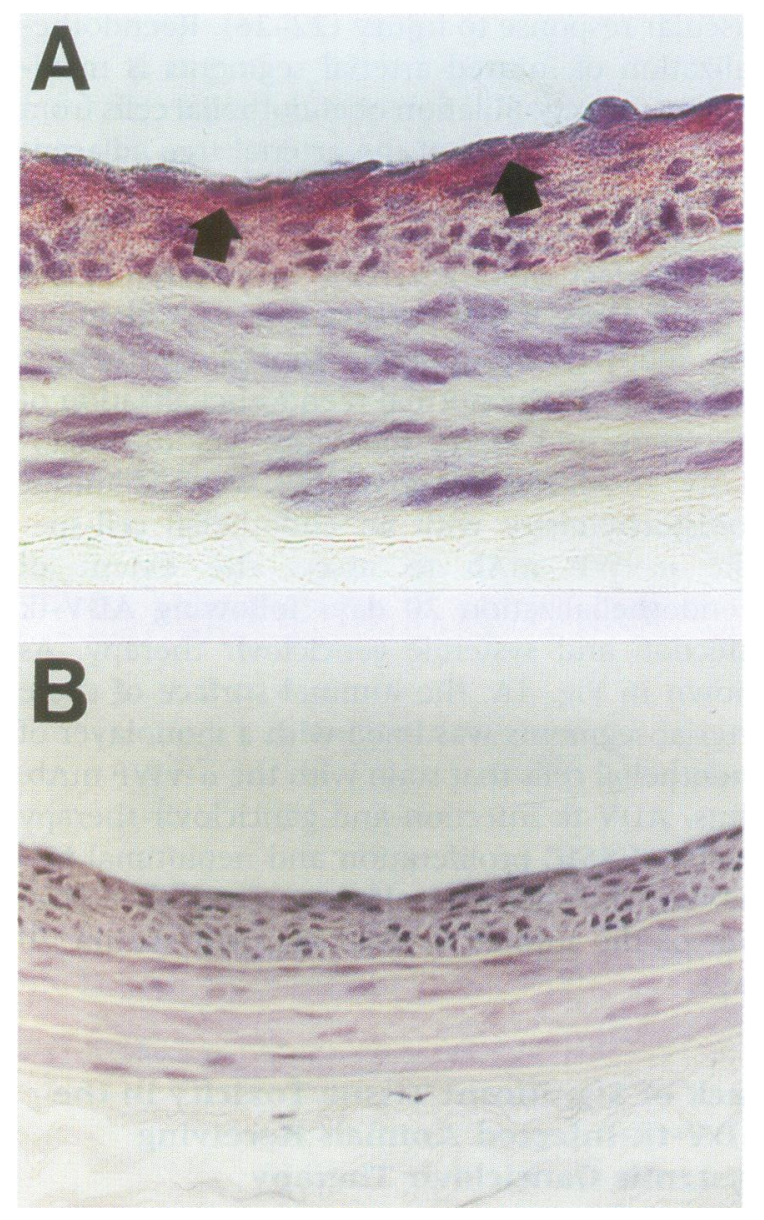

FIG. 4. Reendothelialization in ADV-tk/+GC arteries

Carotid arteries from ADV-tk/ + GC treated animals were harvested at 20 days following balloon injury and subjected to immunohistochemical analysis with a mAb specific for von Willebrand Factor (A), or with an isotype matched control (B). An intact endothelial cell layer is demonstrated by the red staining lining the luminal surface of the artery in Panel A (arrows).

tients $(1,5)$, a reactive VSMC proliferation ensues within the first 6 months after the procedure, leading to clinically significant intimal hyperplasia and restenosis in $30-50 \%$ of the treated arteries (2-5). Intimal hyperplasia following PTCA is likely an exaggerated form of the response to arterial injury common to a wide variety of vascular proliferative disorders including atherosclerosis (1-3). Numerous pharmacologic approaches, including antiplatelet agents, anticoagulants, angiotensin-converting enzyme antagonists, and cytotoxic drugs, have failed to inhibit restenosis in humans (33-37). More recently, genetic approaches have been used both to better understand the molecular mechanisms underlying the VSMC proliferative response to arterial injury, and to form the basis for novel gene-based therapies for restenosis and other vascular proliferative diseases $(14,15,20,38)$. One study has demonstrated that antisense oligonucleotides directed against the c-myb protooncogene could significantly inhibit restenosis when applied to the adventitial surface of the vessel (38). More recently, the intraluminal administration of antisense oligonucleotides directed against PCNA and cdc2 complexed with hemagglutinating virus of Japan coated liposomes was shown to inhibit restenosis in the rat carotid artery model of injury (20). Although encouraging, these antisense approaches may be limited by significant batch to batch variability in the antisense oligonucleotides themselves, and by the lack of a reliable intravascular delivery system.

Replication-defective adenoviruses represent an attractive vector system for programming transient recombinant gene expression in localized segments of the arterial wall. These vectors have been show to efficiently infect VSMCs both in vitro and in vivo (14-17). They can be prepared as high titer stocks and delivered to the intraluminal surface of the vessel using a variety of catheters (14-17). As compared with most other viral vectors, they have a favorable safety profile (17,31,39-41). Thus, adenoviruses do not integrate into the host genome and have not been associated with human malignancies $(28,39-42)$. Furthermore, adenoviruses cause only mild upper respiratory infections in humans (43), and adenovirus vectors have been used safely to vaccinate large numbers of military recruits (42). Most importantly, previous studies have shown that El-deleted replication-defective adenovirus vectors program recombinant gene expression for only 14-21 days after in vivo administration $(17,28,32,44,45)$. This pattern of transient recombinant gene expression is ideally suited to the treatment of restenosis following PTCA.

In the studies described in this report, we have shown that adenovirus-mediated gene transfer of the HSV-tk gene into VSMCs at the time of balloon injury, when combined with a 6-day course of systemic ganciclovir therapy, significantly inhibits medial VSMC proliferation and neointimal formation in the rat carotid artery model of restenosis. A recent report has also demonstrated the efficacy of this approach in inhibiting restenosis in a porcine model of bal- 
loon injury of the iliofemoral artery. The $46 \%$ reduction in neointimal formation by ADV-tk/ + GC therapy in the rat carotid artery model observed in our study was comparable to the $54 \%$ reduction reported by Ohno et al. (15) in the pig model. The finding of efficacy in two different animal models of restenosis is particularly important because previous studies have demonstrated that it is difficult to accurately predict the efficacy of restenosis therapy based on results from a single animal model of arterial injury. Thus, for example, angiotensin-converting enzyme inhibitors (46) and aspirin (47) were both shown to limit neointimal formation in the rat carotid artery injury model, but failed to inhibit restenosis following PTCA in humans $(33,34)$.

It is important to consider the mechanism by which ADV-tk/+GC therapy inhibits neointimal formation and restenosis following arterial injury. The protocol for adenovirus-mediated intravascular gene transfer used in our studies results in efficient in vivo gene transfer into medial VSMCs in the injured arterial segment $(14,15)$. Thus, it is possible that the observed inhibition of restenosis reflects a direct cytotoxic effect of ganciclovir on the adenovirus-infected VSMCs. Alternatively, the inhibitory effects of this approach may reflect the previously described, but poorly understood "bystander effect" associated with HSV-tk expression + ganciclovir treatment $(8,9)$. This effect was first described in tumor cells transduced with the HSV-tk gene and treated with ganciclovir (9). In these initial experiments ganciclovir was shown to be cytotoxic to both transduced and nontransduced tumor cells in the same culture dish. Subsequent studies showed that expression of HSV-tk in only $25 \%$ of cultured primary porcine VSMCs was sufficient to kill approximately $75 \%$ of the cells in the culture dish (15). Although this bystander effect has been clearly demonstrated in vitro, it is currently difficult to assess the role of this cytotoxic mechanism in vivo.

It is noteworthy that the experimental protocol described in this report utilized a 5-min infection with adenovirus as compared with the 20 min incubation used in the porcine model (15). Thus, it may be possible to significantly reduce the times of infection following balloon angioplasty, an important consideration for limiting myocardial ischemia in humans following PTCA. Finally, as opposed to previous protocols (16) which only demonstrated efficient in vivo gene transfer to neointimal VSMCs when adeno- virus infections were performed 7 days after arterial injury, our studies demonstrated significant reductions in restenosis when virus was administered immediately following balloon injury, a protocol which is more feasible for human therapy following PTCA.

It is critically important to carefully assess the safety of any gene therapy protocol involving the in vivo administration of infectious vectors. In this report, we have demonstrated that the local administration of a replication-defective adenovirus vector encoding the HSV-tk gene, when combined with systemic ganciclovir therapy, fails to produce any evidence of tissue toxicity or inflammation. Of equal importance, we did not observe intravascular inflammation or necrosis nor signs of arterial dilatation or aneurysm formation at the site of arterial injury and viral infection. The absence of local and generalized toxicity is in agreement with the findings of Ohno et al., who administered this same virus to localized segments of the pig iliofemoral artery following balloon angioplasty (15). Finally, as was seen in the pig model, we appear to have achieved selective killing of proliferating VSMCs without inhibiting the reendothelialization of the injured arterial segment. This may reflect the transient nature of adenovirus-mediated recombinant gene expression in vivo and the later repopulation of the injured vessel segments by nontransduced endothelial cells that migrated from adjacent uninfected regions of the artery.

The efficacy and safety of ADV-tk followed by ganciclovir therapy in two animal models of restenosis suggests the possible utility of this approach for the therapy of human restenosis following PTCA. However, it will be important to demonstrate the efficacy of this treatment in atherosclerotic models of balloon angioplasty prior to the initiation of human clinical trials.

\section{ACKNOWLEDGMENTS}

The authors would like to thank Lingling $\mathrm{Xu}$ and Hong San, MD, for their technical assistance. This work was supported in part by a grant from Vical Inc., La Jolla, CA.

\section{REFERENCES}

1. Ross R. (1993) The pathogenesis of atherosclerosis: A perspective for the 1990's. Nature 362: 801-809. 
2. Forrester JS, Fishbein M, Helfant R, Fagin J. (1991) A paradigm for restenos is based on cell biology: Clues for the development of new preventive therapies. J. Am. Coll. Cardiol. 17: 758-769.

3. Ip JH, Fuster V, Badimon L, Badimon J, Taubman MB, Chesebro JH. (1990) Syndromes of accelerated atherosclerosis: Role of vascular injury and smooth muscle cell proliferation. J. Am. Coll. Cardiol. 15: 16671687.

4. Schwartz RS, Holmes DR, Topol EJ. (1992) The restenosis paradigm revisited: an alternative proposal for cellular mechanisms. $J$. Am. Coll. Cardiol. 20: 1284-1293.

5. Liu MW, Roubin GS, King SB. (1989) Restenosis after coronary angioplasty. Potential biologic determinants and role of intimal hyperplasia. Circulation 79: 1374-1387.

6. Borrelli E, Heyman R, Hsi M, Evans RM. (1988) Targeting of an inducible toxic phenotype in animal cells. Proc. Natl. Acad. Sci. U.S.A. 85: 7572-7562.

7. Heyman RA, Borrelli E, Lesley J, et al. (1989) Thymidine kinase obliteration: Creation of transgenic mice with controlled immune deficiency. Proc. Natl. Acad. Sci. U.S.A. 86: $2698-2702$.

8. Culver KW, Van Gilder J, Link CJ, et al. (1994) Gene therapy for the treatment of malignant brain tumors with in vivo tumor transduction with the herpes simplex thymidine kinase gene/ganciclovir system. Hum. Gene. Ther. 5: 343-379.

9. Culver KW, Ram Z, Wallbridge S, Ishii H, Oldfield EH, Blaese RM. (1992) In vivo gene transfer with retroviral vector-producer cells for treatment of experimental brain tumors. Science 256: 1550-1552.

10. Breakefield XO, DeLuca NA. (1991) Herpes simplex virus for gene delivery to neurons. New Biol. 3: 203-218.

11. Moolten FL, Wells JM, Heyman RA, Evans RM. (1990) Lymphoma regression induced by ganciclovir in mice beraring a herpes thymidine kinase transgene. Hum. Gene. Ther. 1: 125-134.

12. Moolten FL, Wells JM. (1990) Curability of tumors bearing herpes thymidine kinase genes transferred by retroviral vectors. $J$. Natl. Cancer Inst. 82: 297-300.

13. Plautz G, Nabel EG, Nabel GJ. (1991) Selective elimination of recombinant genes in vivo with a suicide retroviral vector. New Biol. 3: 709-715.

14. Chang MW, Barr E, Seltzer J, et al. (in press) Cytostatic gene therapy for vascular prolifer- ative disorders using a constitutively active form of Rb. Science.

15. Ohno T, Gordon D, San H, et al. (1994) Gene therapy for vascular smooth muscle cell proliferation after arterial injury. Science 265: 781-784.

16. Guzman RJ, Lemarchand P, Crystal RG, Epstein SE and Finkel T. (1993) Efficient and selective adenovirus-mediated gene transfer into vascular neointima. Circulation 88: 2838-2848.

17. Barr E, Carroll J, Kalynych AM, et al. (1994) Efficient catheter-mediated gene transfer into the heart using replication-defective adenovirus. Gene. Ther. 1: 51-58.

18. Clowes AW, Reidy MA, Clowes MM. (1983) Kinetics of cellular proliferation after arterial injury. I. Smooth muscle growth in the absence of endothelium. Lab. Invest. 49: 327333.

19. Lindner V, Olson NE, Clowes AW, Reidy MA. (1992) Inhibition of smooth muscle cell proliferation in injured rat arteries. J. Clin. Invest. 90: 2044-2049.

20. Morishita R, Gibbons GH, Ellison KE, et al. (1993) Single intraluminal delivery of antisense cdc2 kinase and proliferating-cell nuclear antigen oligonucleotides results in chronic inhibition of neointimal hyperplasia. Proc. Natl. Acad. Sci. U.S.A. 90: 8474-8478.

21. Nabel EG, Shum L, Pompili VJ, et al. (1993) Direct transfer of transforming growth factor beta 1 gene into arteries stimulates fibrocellular hyperplasia. Proc. Natl. Acad. Sci. U.S.A. 90: 10759-10763.

22. Baumgartner HR, Muggli R, Tschopp TB, Turitto VT. (1976) Platelet adhesion, release and aggregation in flowing blood: Effects of surface properties and platelet function. Throm. Haem. 35: 124-138

23. Moncada S, Herman AG, Higgs EA, Vane JR. (1977) Differential formation of prostacyclin (PGX or PGI2) by layers of the arterial wall. An explanation for the anti-thrombotic properties of vascular endothelium. Throm. Res. 11: 323-344.

24. Furchgott RF. (1983) Role of endothelium in responses of vascular smooth muscle. Circ. Res. 53: 557-573.

25. Furchgott RF, Zawadzki JV. (1980) The obligatory role of endothelial cells in the relaxation of arterial smooth muscle by acetylcholine. Nature 288: 373-376.

26. Shimokawa H, Vanhoutte PM. (1989) Impaired endothelium-dependent relaxation to aggregating platelets and related vasoactive substances in porcine coronary arteries in 
hypercholesterolemia and atherosclerosis. Circ. Res. 64: 900-914.

27. Lemarchand $\mathrm{P}$, Jones $\mathrm{M}$, Yamada I, et al. In vivo gene transfer and expression in normal uninjured blood vessels using replicationdeficient recombinant adenovirus vectors. Circ. Res. 72: 1132-1138.

28. Stratford-Perricaudet LD, Makeh I, Perricaudet M, Briand P. (1992) Widespread long-term gene transfer to mouse skeletal muscles and heart. J. Clin. Invest. 90: 626630.

29. Eisler A, Falck-Pedersen E, Alvira M, et al. (1993) Quantitative determination of adenovirus-mediated gene delivery to rat cardiac myocytes in vitro and in vivo. Proc. Natl. Acad. Sci. U.S.A. 90: 11498-11502.

30. Engelhardt JF. (1993) Adenovirus-mediated transfer of the CFTR gene to lung of nonhuman primates: Biological efficacy study. Hum. Gene. Ther. 4: 759-769.

31. Zabner J, et al. (1994) Safety and efficacy of repetitive adenovirus-mediated transfer of CFTR CDNA to airway epithelia of primates and cotton rats. Nature Gen. 6: 75-83.

32. Tripathy SK, Goldwasser E, Barr E, Leiden JM. (in press) Stable delivery of physiologic levels of recombinant erythropoietin to the systemic circulation by intramuscular injection of replication-defective adenovirus. Proc. Natl. Acad. Sci. U.S.A.

33. Thornton MA, Gruntzig AR, Hollman J, King SB, Gouglas JS. (1984) Coumadin and aspirin in prevention of recurrence after transluminal coronary angioplasty: A randomized trial. Circulation 69: 721-727.

34. MERCATOR Study Group. (1992) Does the new angiotensin converting enzyme inhibitor cilazapril prevent restenosis after percutaneous transluminal coronary angioplasty? Results of the MERCATOR study: A multicenter, randomized double-blind placebo controlled trial. Circulation 86: 100-110.

35. Ellis SG, Roubin GS, Wilentz J, Douglas JS, King SB. (1989) Effect of 18-24 hour heparin administration for prevention of restenosis after uncomplicated coronary angioplasty. Am. Heart J. 117: 777-782.

36. Landau C, Lange RA, Hillis LD. (1994) Percutaneous transluminal coronary angioplasty. N. Engl. Jour. Med. 330: 981-993.
37. Muller DW, Ellis SG, Topol EJ. (1991) Colchicine and antineoplastic therapy for the prevention of restenosis after percutaneous coronary interventions. J. Am. Coll. Cardiol. 17(Suppl B): 126B-131B.

38. Simons $M$, Edelman ER, DeKeyser JL, Langer R, Rosenberg RD. (1992) Antisense $c-m y b$ oligonucleotides inhibit intimal arterial smooth muscle cell accumulation in vivo. Nature 359: 67-70.

39. Barr E, Leiden JM. (1994) Somatic gene therapy for cardiovascular disease. Trends Card. Med. 4: 57-63.

40. Leiden JM, Barr E. (1994) In vivo gene transfer into the heart. In: Wolff JA (ed). Gene Therapeutics: Methods and Applications of Direct Gene Transfer. Birkhauser, Boston.

41. Chang MW, Leiden JM. (in press) Gene and cell-based therapies for myocardial dysfunction. In: Edelman ER (ed). Molecular Interventions and Local Drug Delivery in Cardiovascular Disease. W. B. Saunders, London.

42. Channock R, Ludwig W, Huebner RJ, et al. (1966) Immunization by selective infection with type 4 adenovirus grown in human diploid tissue cultures. I. Safety and lack of oncogenicity and tests for potency in volunteers. J.A.M.A. 195: 445-452.

43. Horwitz MS. (1990) The adenoviruses. In: Fields BN, Knipe DM (eds). Virology. Raven Press, New York.

44. Yang Y, Nunes FA, Berencsi K, et al. (1994) Cellular immunity to viral antigens limits El-deleted adenoviruses for gene therapy. Proc. Natl. Acad. Sci. U.S.A. 91: 4407-4411.

45. Yang Y, Ertl HCJ, Wilson JM. (1994) MHC class-I restricted cytotoxic T lymphocytes to viral antigens destroy hepatocytes in mice infected with El-deleted recombinant adenoviruses. Immunity 1: 433-442.

46. Powell JS, Clozel J-P, Muller RKM, et al. (1989) Inhibitors of angiotensin-converting enzyme prevent myointimal proliferation after vascular injury. Science 245: 186-188.

47. Volker W, Faber V. (1990) Aspirin reduces the growth of medial and neointimal thickenings in balloon-injured rat carotid arteries. Stroke 21(Suppl 4): IV44-IV45. 